\title{
The Right to Do Wrong: Lying to Parents Among Adolescents and Emerging Adults
}

\author{
Lene Arnett Jensen, ${ }^{1}$ Jeffrey Jensen Arnett, ${ }^{2}$ S. Shirley Feldman, ${ }^{3}$ and Elizabeth Cauffman ${ }^{4}$
}

Received September 23, 2002; revised January 31, 2003; accepted April 23, 2003

\begin{abstract}
In this study, 229 high school students and 261 college students evaluated the acceptability of lying to parents under 19 different circumstances where a person's motive for lying differed. Students also indicated the frequency with which they had lied to their parents about diverse issue such as friends, dates, and money. Results indicated that adolescents and emerging adults quite commonly lied to their parents, and that in part they framed lying to parents as a way to assert the right to autonomy. Emerging adults were less accepting of lying and reported less frequent lying, compared to adolescents. Results also showed the association of sex, personality (self-restraint and tolerance of deviance), and family environment (control and cohesion) upon adolescents' and emerging adults' acceptance of lying to parents and lying behavior.
\end{abstract}

KEY WORDS: adolescence; emerging adulthood; lying; child-parent relations.

\section{INTRODUCTION}

Lying is a common part of human relationships (DePaulo et al., 1996). People lie for a variety of reasons. They may lie as part of self-presentation, in order to present a more favorable image to others. People may also lie in order to minimize conflict, because lying may make disagreements less obvious (De Paulo et al., 1996; Kashy and DePaulo, 1996). Although lying may serve useful functions in these respects, it can also be damaging

\footnotetext{
${ }^{1}$ Lene Arnett Jensen is an Assistant Professor at The Catholic University of America. She received her PhD in 1996 from the Committee on Human Development at the University of Chicago. Her major research interests are adolescent cultural identity formation, adolescentparent relations among immigrants, and cultural-developmental approaches to moral reasoning. To whom corresponding should be addressed at Department of Psychology, Catholic University of America, 4001 Harewood Road, Washington, District of Columbia 20064; e-mail: jensen1@cua.edu.

${ }^{2}$ Jeffrey Jensen Arnett is a Research Associate Professor at the University of Maryland. He received his $\mathrm{PhD}$ from the University of Virginia in 1986. His main research interests are cigarette smoking among adolescents, media use in adolescence, and a wide range of topics in emerging adulthood.

${ }^{3}$ S. Shirley Feldman is Senior Research Scientist in the Division of Child Psychiatry and Behavior at Stanford University. She received her PhD in 1968 from Stanford University. Her major research interests are adolescent sexuality, family influences, and minor deviant behavior by youth.
}

to relationships (Bok, 1978). An exposed lie undermines trust and sows suspicion, because a person who has been lied to is likely to mistrust the person who lied in the future.

There is a paucity of psychological literature pertaining to lying. A limited number of studies have been carried out within different subdisciplines of psychology, with clinical psychologists focusing on lying as a problem behavior (e.g., Stouthamer-Loeber, 1986; StouthamerLoeber and Loeber, 1986), social psychologists focusing on personality and situational correlates of lying (e.g., DePaulo et al., 1996; Kashy and DePaulo, 1996; Lindskold and Waters, 1983; Millar and Tesser, 1987), and developmental psychologists often studying lying among children with reference to Piaget's (1932/1965) moral and cognitive theory (e.g., Bussey, 1992; Peterson, 1995; Peterson et al., 1983; Strichartz and Burton, 1990).

The focus of this study was on lying to parents among adolescents and emerging adults. Lying may be one way

\footnotetext{
${ }^{4}$ Elizabeth Cauffman is an Assistant Professor in the Division of Law \& Psychiatry at Western Psychiatric Institute \& Clinic, University of Pittsburgh. She received her PhD in Developmental Psychology from Temple University and completed a post-doctoral fellowship at the Center on Adolescence at Stanford University. Dr. Cauffman's current research efforts involve the assessment of mental health and psychosocial maturity among juvenile offenders, the exploration of factors associated with female delinquency, and the study of maturity of judgment as it develops during the course of adolescence.
} 
that adolescents seek to establish a greater scope of thoughts and activities to which their parents do not have access. In emerging adulthood, in contrast, lying may decline as parents often grant more autonomy and exert less control. To our knowledge, there is virtually no research addressing lying to parents among adolescents and emerging adults. Here our aim was to begin to address developmental, individual, and family factors that may be related to lying to parents in adolescence and emerging adulthood. Clearly, more research will be needed in this area of parent-child relations.

\section{Predictors of Lying}

Age

Many scholars agree that gaining an increased sense of autonomy within the family is one of the key developmental tasks of adolescence (Grotevant and Cooper, 1988; O'Connor et al., 1996). In the course of their teens, adolescents in Western countries typically gain decisionmaking responsibility for a widening range of areas, including choice of dress, friends, and recreational activities (Dornbusch et al., 1985, 1990; Smetana, 1989).

The boundaries of adolescents' expanding autonomy depend in part on the domain in question (Bregman and Killen, 1999; Grusec and Goodnow, 1994). Research by Turiel (1983) and his colleagues have distinguished between moral, conventional, and personal issues. According to this research, people often make a distinction between moral issues, in which the welfare of others is directly involved (e.g., stealing); conventional issues, which are based on cultural customs and norms (e.g., clothing styles); and personal issues, which are subject only to the individual's preferences. The distinction among domains, however, is partly in the eye of the beholder. Not everyone is likely to distinguish the "moral," "conventional," and "personal" along the same lines. American parents and adolescents often have different views of whether an issue is conventional or personal (Smetana, 1988, 1989; Smetana and Asquith, 1994). In particular, parents tend to define some areas pertaining to substance use and sexual behavior as conventional, and therefore areas in which parents have a legitimate role in defining the limits of their children's behavior, whereas adolescents tend to view these areas as part of their personal domain, nobody's business but their own. Thus adolescents tend to believe the scope of their autonomy should be greater than parents believe it should be.

What happens when adolescents and their parents have different views of the appropriate limits of the adolescent's autonomy? One possible outcome is conflict
(Smetana and Asquith, 1994). Another possible result of differing views of the boundaries of adolescents' autonomy is that adolescents may lie to their parents. If parents attempt to exert influence on an issue that adolescents regard as none of their business, adolescents may feel justified in lying to their parents in order to avoid conflict and to preserve what they regard as the rightful range of their autonomy.

As adolescence comes to an end, conceptions and behaviors pertaining to lying to parents may change. Arnett $(1998,2000)$ has recently proposed emerging adulthood as a conception of the developmental period that follows adolescence in industrialized countries. According to this conception, emerging adulthood extends from the late teens to the mid-to-late 20s. During this period, there is typically a great deal of change and instability as young people explore various life possibilities in love, work, and worldviews (Arnett, 1998). With respect to relationships with parents, emerging adults report improved relations compared to adolescence (O'Connor et al., 1996). Conflict diminishes and reported emotional closeness increases. Emerging adults grow increasingly autonomous, and parents typically adjust to their children's growing maturity by scaling back their attempts to set rules and standards for emerging adults' behavior. For the most part, parents and emerging adults in American society move toward a relationship as friends and near-equals (Arnett, 2002). Although it has not been investigated prior to this study, it could be expected that emerging adults have fewer circumstances when they may have a reason to lie to their parents as parental monitoring and the scope of parental authority diminish.

Sex

Previous studies suggest that there is a sex difference in lying to parents. For example, Keltikangas-Jarvinen and Lindeman (1997) found that among 11, 14 and 17 year olds, boys were more tolerant of lying than girls. Also, in her review of the literature on lying behavior among children and adolescents, Stouthamer-Loeber (1986) found that boys lied more than girls. Furthermore, research with adolescents and emerging adults has shown that males are more accepting of a variety of other transgressions such as academic cheating, sexual betrayal, theft, and physical fighting (Cauffman et al., 2000; Feldman et al., 2000; Jensen et al., 2002; Jessor and Jessor, 1977; KeltikangasJarvinen and Lindeman, 1997). Males are also more likely to engage in many types of problem behavior (e.g., Arnett, 1992; Cochran et al., 1998; Davis et al., 1992; Jensen et al., 2002; Roth and McCabe, 1995). 


\section{Motives for Lying}

Whereas there may be age and sex differences in acceptance of lying to parents, the degree of acceptance within all groups is likely to depend on the motive for the lie. Keltikangas-Jarvinen and Lindeman (1997) found that adolescents between the ages of 11 and 17 regarded lying as more acceptable when a person's motive was "positive" (e.g., prosocial) as opposed to "negative" (e.g., selfgain), and when a person transgressed unintentionally as opposed to intentionally. Lee and Ross (1997) found that 12-19 year olds saw lying as more acceptable when the motive was altruistic rather than exploitative, and when the motive pertained to being polite rather than providing information. In a study of college students, Lindskold and Waters (1983) found that altruistic lies were more acceptable than lies aimed at self-enhancement; in turn selfenhancement lies were more acceptable than lies that endangered the welfare of others. In this study, we included motives that previous literature has addressed (e.g., prosocial aims and self-interest), as well as motives that may be of particular relevance when adolescents and emerging adults lie to parents (e.g., assertion of autonomy, rebellion against parents, a perception of parents as old-fashioned).

\section{Personality Characteristics}

Lying to parents may also be related to personality characteristics. For example, Kashy and DePaulo (1996) reported that liars are more likely to be Machiavellian, socially adroit, and self-conscious. In this study, we focused on self-restraint and tolerance of deviance, two characteristics addressed by previous research on adolescence (Offer, 1969). Research with adolescents and emerging adults has shown that both of these personality characteristics are related to transgressions, such as academic cheating, betrayal of a friend's secret, and cheating on one's romantic partner (Cauffman et al., 2000; Feldman et al., 2000; Jensen et al., 2002).

\section{Family Characteristics}

Whereas lying to parents may be related to characteristics of the liar, it may also be related to characteristics of the family environment within which the lying occurs. In this study we focused on 2 well-established dimensions of the family environment: control and cohesion (Moos and Moos, 1974). In families where parents exert a high degree of control by setting strict rules and allowing for few deviations from these rules, adolescents and emerging adults may lie more in an attempt to preserve what they regard as the rightful range of their autonomy (Smetana and Asquith, 1994). In contrast, in families with a high degree of cohesion, adolescents and emerging adults may lie less because they feel that their parents will be supportive of their thoughts and activities. Also, adolescents and emerging adults who form part of cohesive families may be less willing to lie and thereby risk losing trust with parents who are supportive, committed, and helpful.

\section{Research Hypotheses for the Present Study}

In light of the above literature, we proposed the following hypotheses: (1) Emerging adults would be less accepting of lying to parents and would report lower frequencies of lying, compared to adolescents. (2) Male participants would be more accepting of lying to parents and would report more frequent lying, compared to female participants. (3) Acceptance of lying would vary by motive, specifically motives pertaining to assertion of autonomy from parents and prosocial intentions would be motives that would render lying most acceptable. (4) Acceptance of lying to parents and lying behavior would be negatively related to self-restraint, but positively related to tolerance of deviance. (5) Acceptance of lying to parents and lying behavior would be negatively related to family cohesion, but positively related to family control.

\section{METHOD}

\section{Participants}

Participants were 229 high school students $(M=$ 15.6 years, $\mathrm{SD}=1.08)$ and 261 college students $(M=$ 20.4 years, $\mathrm{SD}=1.23)$. The high school students $(55 \%$ female) attended a public high school on the West coast of the United States. With respect to ethnicity, $76 \%$ were European American, $8 \%$ were Asian American, $8 \%$ were African American, and 8\% indicated "other" or provided no information. Twenty-five percent of the fathers of the high school students had obtained less than a college degree, whereas the comparable figure was $34 \%$ for the mothers. Seventy-one percent of the high school students indicated that they had a GPA consisting mostly of As, or half As and half Bs. Forty-three percent of students indicated that they were employed part time.

The college students (65\% female) attended a state university located in the American Midwest. With respect to ethnicity, $83 \%$ were European American, $8 \%$ were Asian American, 7\% were African American, and 2\% indicated "other." Fifty-two percent of the students' fathers and $57 \%$ of their mothers had obtained less than a college 
degree. With respect to GPA and work, $40 \%$ had a GPA consisting mostly of As or half As and half Bs, and 64\% were employed.

The high school and college samples differed significantly on father's education, mother's education, GPA, and employment. Subsequent statistical analyses controlled for these differences.

\section{Materials}

Participants completed a battery of questionnaires. For this study, the relevant measures were the following:

\section{Demographic Information}

Participants provided information about their age, sex, ethnicity, school grade, GPA, work involvement, and parental education.

\section{Lying Behavior}

On 5-point scales, participants rated the frequency with which they had lied to their parents about 6 different issues within the last year $(1=$ never, $5=$ ten or more times). The 6 issues pertained to: money, sexual behavior, friends, parties, dating, and alcohol and drug use. To create a composite measure of lying behavior, frequencies across the 6 behaviors were averaged. The overall frequency of lying behavior score had good internal reliability $(\alpha=$ $0.84,6$ items).

\section{Acceptance of Lying to Parents}

Participants read a vignette where the protagonist lies to his or her parents. As described in the introduction, the literature shows a sex difference with males lying more than females. To take into account a potential significance of the sex of the vignette protagonist, we included protagonists of each sex. We randomly assigned participants to receive the vignette with either a female or male protagonist. The vignette for the female protagonist read as follows: "Janet, age 17, is determined to spend the night with her boyfriend. Since she knew her parents would not allow her to do this, she lied and said she was going to spend the night at Susan's house. For each item, rate how acceptable it is for Janet to lie to her parents. How acceptable is it if Janet...." Participants were then presented with 19 different circumstances where the protagonist's motive for transgressing differed. Participants evaluated each of the 19 different motives on 4-point scales $(1=$ totally unacceptable, $2=$ somewhat unacceptable, $3=$ somewhat acceptable, $4=$ totally acceptable).

To generate the motives, we reviewed literature on lying and moral psychology (e.g., Jensen, 1996; Keltikangas-Jarvinen and Lindeman, 1997; Kohlberg, 1981, 1984; Lee and Ross, 1997; Lindskold and Waters, 1983). We also conducted 3 focus groups with $4-6$ college students. Finally, we piloted our motives with 45 college students in order to obtain data on variability, ceiling and floor effects, and to make final editorial corrections to the wording of motives. (Students involved in the process of generating motives did not participate in the study.) The 19 final motives were diverse. They pertained to the following general types of motives: conformity, redressing perceived inequity, personality and prior history of the perpetrator, desire for autonomy, prosocial intentions, avoidance of harm to others, opportunism, and disconnection from parents (see Table II for specific examples of motives). On the questionnaire, the order of the motives was randomized.

A principal components analysis (PCA) with varimax rotation on the 19 motives did not yield coherent factors. Attempts to create a priori clusters (pertaining to disconnection from parents, promoting self-interest, and concern for others' welfare) resulted in highly intercorrelated composite scores (e.g., correlation coefficients between 0.72 and 0.78 ). Thus, we elected not to use the factor or a priori composite scores. Instead we examined separately the 19 item scores in most analyses. In some analyses, we also used the overall acceptance score in which we averaged the ratings across the 19 motives. The total acceptance of lying score had good reliability $(\alpha=0.93$, 19 items).

\section{Self-Restraint}

The measure was a subscale from the Weinberger Adjustment Inventory (WAI, Weinberger, 1997). The selfrestraint scale assesses 4 dimensions: impulse control, suppression of aggression, consideration of others, and responsibility. A sample item is: "Before I do something, I think about how it will affect people around me." Participants rated 30 items on a 5 -point scale $(1=$ false, $5=$ true $)$. The scale had good internal reliability $(\alpha=$ $0.87,30$ items). The self-restraint scale has been found to have good psychometric properties and to display convergent, discriminant, and predictive validity (Feldman and Weinberger, 1994; Weinberger, 1997). 


\section{Tolerance of Deviance}

Participants rated the acceptability of transgressions involving physical violence toward a peer, academic cheating, and betraying a friend's secret. They rated the acceptability of these behaviors under 18 or 19 different circumstances on 4-point scales $(1=$ totally unacceptable, $4=$ totally acceptable). The internal reliability scores for each of the 3 different transgressions were satisfactory (physical violence: $\alpha=0.91,19$ items; academic cheating: $\alpha=0.93,19$ items; and betraying a friend's confidence: $\alpha=0.86,18$ items). Also, the acceptance measures of each of the 3 types of transgressions have shown criterion validity (Cauffman et al., 2000; Feldman et al., 2000; Jensen et al., 2002). The tolerance of deviance score (developed for this study) consisted of the mean of the scores of the acceptability of the 3 transgressions. The mean scores for the 3 types of transgressions were all significantly intercorrelated (Spearman's correlations were the following: academic cheating with physical violence, $\rho=0.48, p<0.01$; academic cheating with betrayal of friend's confidence, $\rho=0.28, p<0.01$; betrayal of friend's confidence with physical violence, $\rho=$ $0.44, p<0.01)$.

\section{Family Cohesion and Family Control}

These measures were 2 subscales from the Family Environment Scale (FES; Moos and Moos, 1974). Each subscale consists of 9 items with a 2 -point scale $(1=$ true, $2=$ false . The family cohesion scale assesses the degree of commitment, help, and support that family members provide for one another. An example of an item is: "There is a feeling of togetherness in our family." The scale had adequate internal reliability $(\alpha=0.76)$. The family control scale assesses the extent to which set rules and procedures are used to run family life. A sample item is: "There is a strong emphasis on following rules in our family." The scale had adequate internal reliability $(\alpha=0.74)$.

\section{Procedure}

Students completed questionnaires during 1 class period (about $45 \mathrm{~min}$ ). Both college and high school students provided active informed consent, and parents of high school students also provided informed consent. Among college students, approximately $99 \%$ of those invited to participate in the study elected to do so. Among high school students, $8 \%$ were withheld from the study by their parents and approximately $5 \%$ of students themselves elected not to participate. For college students, taking part in the study was one of several ways to satisfy a class requirement. High school students were given credit for returning parental consent forms (irrespective of whether parents consented or declined participation on behalf of their child). To encourage truthful responses, we instructed students not to write their names on the questionnaire in order to make the study completely anonymous and confidential.

\section{RESULTS}

\section{Analysis Guidelines}

The acceptance of lying to parents variable was not normally distributed because most students regarded lying as unacceptable. Nonparametric statistical analyses are the most appropriate for such situations. We conducted both nonparametric and parametric analyses and obtained similar results. We report the results of the parametric analyses here because these analyses allow for assessment of interactions, the use of control variables, and are more easily interpreted. However, for correlational analyses we report results from analyses using Kendall's $\tau$-b and Spearman correlations (nonparametric tests).

\section{Lying Behavior: Prevalence and Relation to Age and Sex}

Lying to parents was indeed a frequent behavior among the adolescents and emerging adults. Figure 1 shows the percentages of students who had lied to their parents about 6 different issues at least once within the past year. As can be seen, the percentage of high school students who had lied about the different issues ranged from 32 to $67 \%$ whereas for college students the range was $28-50 \%$. Eighty-two percent of all students indicated that they had lied to their parents about at least 1 of the 6 issues during the past year.

We hypothesized that lying to parents would be more common among adolescents than emerging adults and more common among males than females. To test these hypotheses, we conducted a 2-way multivariate analysis of covariance (MANCOVA) on the 6 lying behaviors (issues) with age (high school and college) and sex of student as between-subjects variables. Because high school and college students differed on GPA, father's education, mother's education, and employment, we entered these variables as covariates in order to remove their effects on the dependent variables. Of the covariates, only GPA reached significance, $F(5,432)=6.79, p<0.001$. As predicted, there were main effects for age, $F(5,432)=$ 14.56, $p<0.001$, and sex, $F(5,432)=2.29, p<0.05$. As seen in Table I, high school students lied more often 


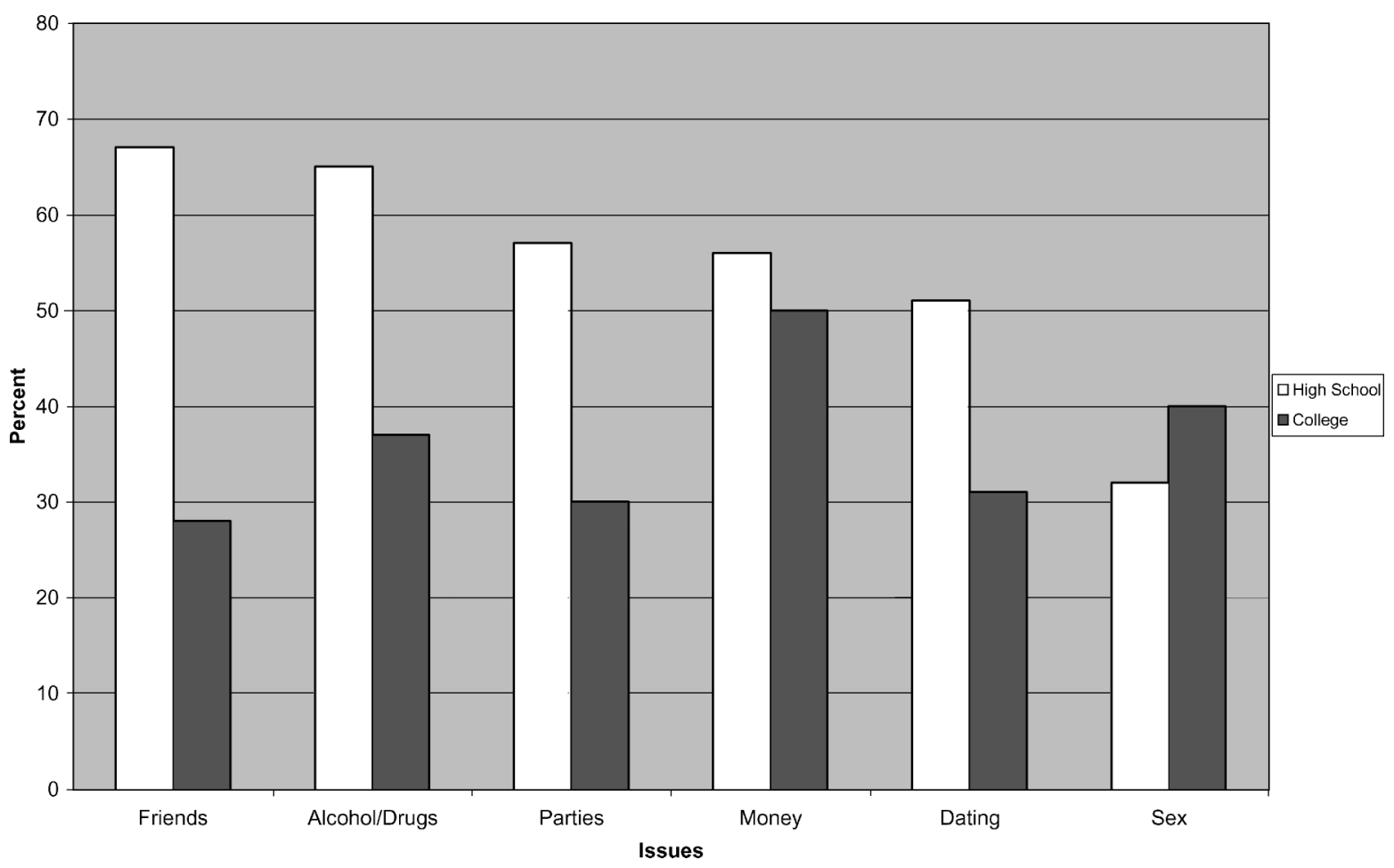

Fig. 1. Frequencies for lying to parents by high school and college students about diverse issues.

than college students on 4 of 6 behaviors. Males reported lying more than females on 2 of 6 behaviors. The sex by age interaction term was not significant.

\section{Evaluations of Lying in Relation to Age and Sex}

To test our hypotheses that lying would be more acceptable to adolescents than emerging adults and to males than females, we carried out a 3-way MANCOVA on ac-

Table I. Comparisons by Age and Sex of Frequency of Lying to Parents

\begin{tabular}{lcccccccc}
\hline & \multicolumn{3}{c}{ Issues lied about } & & \multicolumn{3}{c}{ Mean scores } \\
\cline { 2 - 3 } \cline { 7 - 8 } & H.S. & Col. & $F$ & & Male & Female & $F$ \\
\hline Friends & 2.57 & 1.56 & $65.68^{* * *}$ & & 2.14 & 2.00 & 1.56 \\
Money & 2.32 & 1.94 & $9.03^{* *}$ & & 2.32 & 1.94 & $10.57^{* *}$ \\
Parties & 2.20 & 1.67 & $17.07^{* * *}$ & & 1.99 & 1.87 & 0.98 \\
Alcohol/drug use & 2.18 & 1.93 & 2.73 & & 2.19 & 1.91 & $4.00^{*}$ \\
Dates/dating & 2.12 & 1.62 & $15.57^{* * *}$ & & 1.89 & 1.86 & 0.06 \\
Sexual behavior & 1.78 & 1.88 & 0.49 & & 1.82 & 1.84 & 0.04 \\
\hline
\end{tabular}

Note. (a) The mean scores are for lying to parents about an issue within the past year with $1=$ never, $2=$ once, $3=$ two to five times, $4=$ six to nine times, $5=$ ten or more times. (b) H.S. $=$ high school students, Col. = college students. (c) Standard deviations (SDs): H.S., 1.29-1.45; Col., 0.37-1.30; Male, 1.23-1.54; Female, 1.12-1.29.

${ }^{*} p<0.05 ;{ }^{* *} p<0.01 ;{ }^{* * *} p<0.001$. ceptance of lying with age, sex of student, and sex of vignette protagonist as between-subject variables. Of the covariates (the same ones were entered as for the analysis above), only GPA was significant, $F(18,444)=$ $1.89, p<0.05$. As predicted, there were main effects for age, $F(18,444)=5.36, \quad p<0.001$, and sex, $F(18,444)=2.17, \quad p<0.01$. Analyses of individual items indicated that high school students regarded lying to parents as more acceptable than college students on 15 of 19 motives. Likewise, males judged lying to parents as more acceptable than females on 15 of 19 motives.

There was also a significant main effect for sex of the vignette protagonist, $F(18,444)=3.55, p<0.001$. However, an examination of individual motives showed significant effects for only 3 of the 19 motives ("did not want to get her boyfriend in trouble," $F(18,444)=11.06$, $p<0.001$; "did not want her parents to prevent her from going," $F(18,444)=3.96, p<0.05$; "knew her boyfriend was having trouble and needed her support," $F(18,444)=18.78, p<0.001)$. For each of these 3 motives, participants regarded lying as more acceptable for a male than female protagonist. Because significant main effects occurred for only 3 of the 19 motives, we conclude that effects for sex of the vignette protagonist were sporadic. 


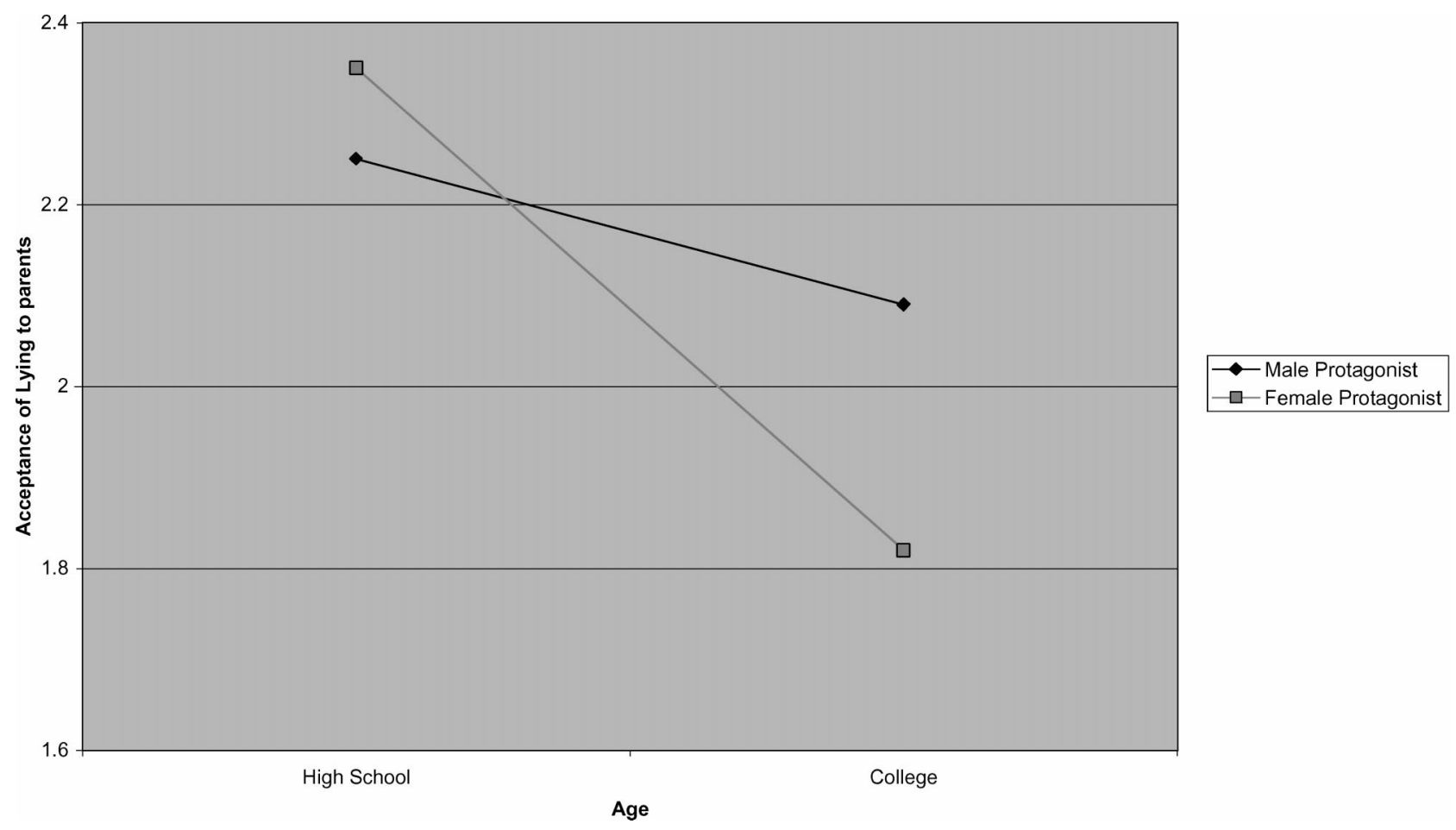

Fig. 2. The interaction of age with sex of vignette protagonist on acceptance of lying to parents.

There were 2 significant interaction effects. One was between age of participant and sex of the vignette protagonist, $F(18,444)=2.26, p<0.01$. Analyses of individual items indicated that college students were particularly unaccepting of lying by a female protagonist for 12 of the 19 individual motives. Figure 2 illustrates the interaction effect for the overall acceptance of lying score.

The second significant interaction was between sex of participant and sex of vignette protagonist, $F(18,444)=$ $2.26, p<0.01$. However, an inspection of the significance levels for each of the 19 motives showed a significant result for only 1 of the motives ("did not want her boyfriend to get in trouble," $F(18,444)=5.81, p<0.05)$. Female participants were particularly unaccepting of lying by a female protagonist given this motive.

\section{Acceptance of Lying in the Context of Different Motives}

To test the hypothesis that acceptance of lying to parents varies as a function of motive, we conducted repeated measures analyses of variance (ANOVAs) with motive as a within-subject factor. Motive had a highly significant influence on the acceptability of lying to parents for the sample as a whole, $F(18,450)=92.9, p<0.001$, as well as for high school students, $F(18,207)=48.7, p<$ 0.001 , college students, $F(18,243)=49.0, p<0.001$, males, $F(18,172)=32.9, \quad p<0.001$, and females, $F(18,275)=62.7, p<0.001$.

Next, we calculated Kendall's correlation coefficients in order to assess whether the different groups ranked motives in similar or different ways. High school and college students ranked motives in a highly similar way, $\tau-\mathrm{b}=$ $0.74, p<0.001$, as did males and females, $\tau-\mathrm{b}=0.81$, $p<0.001$.

Next, we determined which motives were most and least acceptable. We carried out analyses for the sample as a whole because the analyses described immediately above indicated that there were no significant differences between groups (by age and sex) in how the motives were rank ordered. We carried out paired $t$ tests with Bonferoni adjustments on the 4 most acceptable motives and the 4 least acceptable motives. Table II lists the most and least acceptable motives. Results indicated that each of the most acceptable motives differed significantly from each of the least acceptable motives. Among the most acceptable motives, motives 1 and 2 differed significantly from motives 3 and 4, but motives 1 and 2 did not differ significantly from each other nor did motives 3 and 4. Among the least 
Table II. The Most and Least Acceptable Motives for Lying to Parents

\begin{tabular}{lll}
\hline & \multicolumn{2}{c}{ All participants } \\
\cline { 2 - 3 } & $M$ & $S D$ \\
\hline Most acceptable & & \\
1. Knew her boyfriend was having trouble and needed her support & 2.64 & 1.04 \\
2. Felt she had the right to make her own decisions & 2.59 & 1.00 \\
3. Knew her family was having trouble and didn't want to add & 2.39 & 0.97 \\
$\quad$ additional stress & & \\
4. Did not want her boyfriend to get in trouble & 2.37 & 0.98 \\
Least acceptable & 1.79 & 0.87 \\
5. Wanted to rebel against her parents & 1.77 & 0.95 \\
6. Wanted to get even with her parents for lies that they had told her & 1.72 & 0.85 \\
7. Wanted to see if she could get away with it & 1.64 & 0.82 \\
8. Knew that her friends told similar lies to their parents & & \\
\hline
\end{tabular}

Note. (a) We present here items for a female vignette protagonist. There were comparable items for a male protagonist. (b) $1=$ totally unacceptable, $2=$ somewhat unacceptable, $3=$ somewhat acceptable, $4=$ totally acceptable.

acceptable motives, the only significant difference occurred between motives 5 and 8 .

\section{Correlates of Acceptance of Lying and Lying Behavior}

We hypothesized that acceptance of lying to parents and lying behavior would be negatively correlated with self-restraint and family cohesion, but positively correlated with tolerance of deviance and family control. As seen in Table III, the results of Spearman correlation analyses mostly supported these hypotheses. The exceptions were that only for college students did family control correlate significantly with evaluation of lying, and only for males did family cohesion correlate significantly with lying behavior when groups were analyzed separately.

\section{Predicting Acceptance of Lying and Lying Behavior}

Finally, we used path analytic techniques (Asher, 1983) to assess paths by which the demographic, personality, and family variables were related to acceptance of lying and to lying behavior. Path analytic techniques are preferred over structural equation modeling when the sample is relatively small, the theoretical model is not completely specified, and when the analyses are to be used inductively rather than for testing a fully articulated theory (Biddle and Marlin, 1987). As seen in Table IV, age, self-restraint, and tolerance of deviance predicted acceptance of lying to parents. In turn, acceptance of lying predicted lying behavior. Also, self-restraint and family control made independent contributions to lying behavior. The model for acceptance of lying accounted for $36 \%$ of the variance, and the model for lying behavior accounted for $23 \%$ of the variance.

Table III. Correlates of Acceptance of Lying to Parents (Total Score) and of Lying Behavior (Total Score)

\begin{tabular}{lccccc}
\hline & All & H.S. & Col. & Male & Female \\
\hline Acceptance of lying & & & & & \\
$\quad$ Tolerance of deviance & $0.61^{* * *}$ & $0.59^{* * *}$ & $0.59^{* * *}$ & $0.54^{* * *}$ & \multicolumn{1}{c}{$0.60^{* * *}$} \\
$\quad$ Self-restraint & $-0.37^{* * *}$ & $-0.34^{* * *}$ & $-0.36^{* * *}$ & $-0.31^{* * *}$ & $-0.35^{* * *}$ \\
Family cohesion & $-0.13^{* *}$ & $-0.18^{* *}$ & -0.04 & $-0.23^{* * *}$ & -0.05 \\
Family control & -0.10 & -0.06 & $-0.11^{*}$ & -0.06 & -0.06 \\
Lying behavior & & & & & \\
$\quad$ Tolerance of deviance & $0.31^{* * *}$ & $0.26^{* * *}$ & $0.27^{* * *}$ & $0.34^{* * *}$ & $0.24^{* * *}$ \\
$\quad$ Self-restraint & $-0.41^{* * *}$ & $-0.47^{* * *}$ & $-0.34^{* * *}$ & $-0.41^{* * *}$ & $-0.39^{* * *}$ \\
Family cohesion & $-0.12^{* *}$ & -0.07 & -0.08 & $-0.22^{* *}$ & -0.06 \\
Family control & $0.17^{* * *}$ & $0.14^{*}$ & $0.16^{* *}$ & $0.20^{* *}$ & $0.16^{* *}$ \\
\hline
\end{tabular}

Note. All = all participants, H.S. $=$ high school students, Col. $=$ college students

${ }^{*} p<0.05 ;{ }^{* *} p<0.01 ;{ }^{* * *} p<0.001$. 
Table IV. Regression on Acceptance of Lying and Lying Behavior of Demographic, Family, and Personality Variables

\begin{tabular}{|c|c|c|c|c|c|c|}
\hline & \multicolumn{3}{|c|}{ Acceptance of lying } & \multicolumn{3}{|c|}{ Lying behavior } \\
\hline & $B$ & $\beta$ & $t$ & $B$ & $\beta$ & $t$ \\
\hline Age & -0.122 & -0.088 & $-2.02^{*}$ & -0.172 & -0.094 & -1.90 \\
\hline Sex & 0.002 & 0.001 & 0.03 & 0.156 & 0.084 & 1.67 \\
\hline Family cohesion & -0.009 & -0.003 & -0.07 & 0.154 & 0.043 & 0.86 \\
\hline Family control & 0.194 & 0.079 & 1.89 & -0.535 & -0.165 & $-3.47^{* *}$ \\
\hline Self-restraint & -0.144 & -0.12 & $-2.34^{*}$ & -0.523 & -0.330 & $-5.70^{* * *}$ \\
\hline Tolerance deviance & 0.977 & 0.515 & $10.34^{* *}$ & 0.013 & 0.005 & 0.08 \\
\hline \multirow[t]{2}{*}{ Acceptance of lying } & & & & 0.236 & 0.180 & $3.07^{* *}$ \\
\hline & \multicolumn{3}{|c|}{ Adjusted $R^{2}=0.36^{* * *}$} & \multicolumn{3}{|c|}{ Adjusted $R^{2}=0.23^{* * *}$} \\
\hline
\end{tabular}

${ }^{*} p<0.05 ;{ }^{* *} p<0.01 ;{ }^{* * *} p<0.001$

\section{DISCUSSION}

Before we discuss key findings, some caveats are necessary. First, the present sample was one of convenience and hence generalizations must be made with caution. Most participants were White, and they came from 2 regions of the country. On the one hand, including 2 rather than 1 region of the country increases generalizability. On the other hand, region of country and age were confounded. To address this issue, we controlled for differences between the adolescent and emerging adult groups of which we were aware (i.e., GPA, father's education, mother's education, and employment). A second caveat with respect to this study is the fact that participants evaluated lying to parents in response to only one vignette. Again, this limits generalizability, even if most of the hypotheses based on a general literature rather than a literature pertaining to the topic of the vignette were supported. Third, self-report measures pertaining to lying may be influenced by social desirability bias. Still, sizable proportions of participants in the study readily admitted to lying.

\section{Lying to Parents Among Adolescents and Emerging Adults}

As adolescents seek to gain increasing autonomy within the family, they and their parents must come to new understandings of where parents' decision-making on behalf of their child ends and adolescents' right to make their own decisions begins. At times, this situation leads to conflict between parents and adolescents (Smetana, 1988). The present results suggest that at times it also means that adolescents feel that they are justified in lying to their parents. Thus, the majority of high school students in this study had lied to their parents in the past year about a variety of issues (e.g., friends, parties, dating), and among the motives that the high school students found most acceptable for lying to parents was that the person "felt she (he) had a right to make her (his) own decisions." More high school than college students indicated that lying for this reason was acceptable.

College students reported lying less frequently to their parents than high school students did. It is unlikely that this is because emerging adults have less to lie about, given the high rates of behaviors such as drinking, drug taking, and premarital sex among people in their 20s (Arnett, 2000). Instead it may be that as young people enter emerging adulthood, their parents grant them more autonomy and make fewer attempts to monitor and control their behavior. In fact, the college students in this study did report lower levels of family control, compared to the high school students, $F(8,435)=6.14, p<0.05$. As the autonomy of emerging adults increases, their parents feel less entitled to control their behavior and emerging adults have fewer occasions to lie. Future research might fruitfully examine factors contributing to the decrease in lying to parents among emerging adults. It would be especially useful to distinguish between the experiences of emerging adults who live at home and emerging adults who have moved out (Arnett, 2002), which we did not do in this study. Such a distinction would allow one to consider degree of contact between parent and child.

It is worth noting that although college students in this study were less likely than high school students to report lying to their parents, a notable proportion of college students had lied to their parents at least once in the past year (ranging from 28 to $50 \%$ for the different issues). This suggests that college students, like high school students, may lie to their parents when they believe it is necessary in order to avoid conflict and to preserve what they regard as their right to make decisions independently of their parents' influence. 


\section{The Family Environment and the Personality of the Liar}

The findings regarding the family environment support the interpretation that adolescents and emerging adults lie to their parents as a way to carve out an autonomous decision-making domain. Specifically, the more parents exercised control, the more likely high school and college students were to report lying. Of course, it is also possible that parents become more controlling in response to the discovery that their children are lying to them.

We predicted and found that in cohesive families adolescents and emerging adults lied less and were less accepting of lying. Also, our findings suggest that family cohesion may discourage males, in particular, from lying to their parents.

Whereas the family environment is important, we also further our understanding by taking account of the personality of the liar (Kashy and DePaulo, 1996). The present results indicated that among high school and college students, those who lie are likely to be low on selfrestraint and high on tolerance of deviance. Indeed the personality variables constituted 2 of the 3 significant predictors of acceptance of lying. In turn, acceptance of lying and self-restraint were 2 of the 3 significant predictors of lying behavior. Previous research has shown that self-restraint and tolerance of deviance are associated with a variety of moral transgressions, including academic cheating, betrayal of one's romantic partner, stealing, and physical assault (Dryfoos, 1990; Feldman et al., 2000; Feldman and Weinberger, 1994; Jessor and Jessor, 1977; McCord, 1990). Persons who lie to their parents, then, appear to have underlying characteristics that also make them likely to engage in other problem behaviors.

\section{SEX AND AGE EFFECTS}

As we predicted, males were more accepting of lying to parents than females. However, in terms of actual lying behavior, males lied more than females on only 2 of the 6 issues (pertaining to money and alcohol/drugs). This finding begins to suggest that among adolescents and emerging adults sex differences are neither consistent nor pervasive in lying to parents. One possibility is that during this age period females are as concerned as males with carving out areas of autonomy from their parents while avoiding conflict.

Interestingly, college students were more accepting of lying by a male protagonist than a female protagonist, whereas high school students evaluated lying by male and female protagonists in the same way. This finding was unexpected. The reasons for it are not clear and await future research.

\section{The Influence of Motives Upon Evaluation}

The nature of the motive for lying to parents was significantly related to the acceptability of lying. As discussed above, the right to lie to one's parents in order to preserve autonomy was a motive that the adolescents and emerging adults placed at the top in justifying lying behavior. The results also showed that prosocial intentions were among the motives that rendered lying most acceptable. Of the top 4 motives for lying, 3 were prosocial. Thus students were more accepting of the protagonist lying to her (his) parents when "her boyfriend was having trouble and needed her support," "she did not want her boyfriend to get in trouble," and "she knew her family was having trouble and she didn't want to add additional stress." Our findings then are consistent with earlier reports that have found that positive, prosocial, and altruistic motives for lying are viewed the most favorably by adolescents and emerging adults (Keltikangas-Jarvinen and Lindeman, 1997; Lee and Ross, 1997; Lindskold and Waters, 1983).

The least acceptable motives for lying in this study were varied. One of the least acceptable motives centered on rebellion ("she wanted to rebel against his parents"). Adolescents and emerging adults may desire autonomy from their parents but they do not regard this as synonymous with rebelling against their parents, and clearly they do not regard rebellion as an acceptable motive for lying (Smetana, 1989; Smetana and Asquith, 1994). Only $23 \%$ of all participants regarded rebellion as an acceptable motive to lie to one's parents whereas $60 \%$ regarded the assertion of an autonomous right to make decisions as an acceptable motive (i.e., totally acceptable or somewhat acceptable). If lying to parents is one way to attain autonomy while avoiding conflict, lying to express rebellion is likely to only exacerbate conflict.

Among the other least acceptable motives for lying to one's parents was conformity ("she knew that her friends told similar lies to their parents"). Conformity to peers peaks in early to mid-adolescence and declines in late adolescence (Berndt, 1979, 1996). Only 17\% of the high school and colleges students in this study regarded conformity as an acceptable reason for lying. Late adolescents and emerging adults place a high value on independence; in fact, making independent decisions is a defining psychological characteristic of emerging adulthood (Arnett, 1997, 1998, 2000) and this may include independence from peers when making decisions. 
Finally, lying as a challenge behavior ("she wanted to see if he could get away with it") or as a revenge ("she wanted to get even with her parents for lies that they had told her") were also regarded as among the least acceptable motives for lying to parents. Other research on academic cheating, fighting with peers, and sexual betrayal has similarly shown that adolescents and emerging adults regard motives pertaining to revenge and challenge behavior as unacceptable (Cauffman et al., 2000; Feldman et al., 2000; Jensen et al., 2002).

\section{CONCLUSION}

This study suggests that many adolescents and emerging adults lie to their parents even though they do not strongly approve of such behavior. The tendency to lie to parents, however, is not universal but is associated with age (developmental level), sex, the family environment, and personality. Future research on this topic could take a variety of directions, including a developmental approach to the meaning and uses of lying in the relationship between parents and their children.

\section{ACKNOWLEDGMENT}

We thank Lexy Kleeman-Keller for assistance in collecting and coding data.

\section{REFERENCES}

Arnett, J. J. (1992). Reckless behavior in adolescence: A developmental perspective. Dev. Rev. 12: 339-373.

Arnett, J. J. (1997). Young people's conceptions of the transition to adulthood. Youth Soc. 29: 1-23.

Arnett, J. J. (1998). Learning to stand alone: The contemporary American transition to adulthood in cultural and historical context. Hum. Dev. 41: 295-315.

Arnett, J. J. (2000). Emerging adulthood: A theory of development from the late teens through the twenties. Am. Psychol. 55: 469-480.

Arnett, J. J. (2002). Emerging Adulthood: Paths of Development From the Late Teens Through the Twenties. Manuscript submitted for publication.

Asher, H. B. (1983). Causal Modeling. Sage, Newbury Park, CA.

Berndt, T. J. (1979). Developmental changes in conformity to peers. Dev. Psychol. 15: 608-616.

Berndt, T. J. (1996). Transitions in friendship and friends' influence. In Graber, J. A., Brooks-Gunn, J., and Petersen, A. C. (eds.), Transitions Through Adolescence: Interpersonal domains and context. Erlbaum, Mahwah, NJ.

Biddle, B. J., and Marlin M. M. (1987). Causality, confirmation, credulity, and structural equation modeling. Child Dev. 58, 4-17.

Bok, S. (1978). Lying: Moral Choice in Public and Private Life. Vintage Books, New York.

Bregman, G., and Killen, M. (1999). Adolescents' and young adults' reasoning about career choice and the role of parental influence. $J$. Res. $n$ Adolesc. 9: 253-275.
Bussey, K. (1992). Lying and truthfulness: Children's definitions, standards, and evaluative reactions. Child Dev. 63: 129-137.

Cauffman, E., Feldman, S. S., Jensen, L. A., and Arnett, J. J. (2000) The (un)acceptability of violence against peers and dates among adolescents and young adults. J. Adolesc. Res. 15: 672-693.

Cochran, J. K., Wood, P. B., Sellers, C. S., Wilkerson, W., and Chamlin, M. B. (1998). Academic dishonesty and low self-control: An empirical test of a general theory of crime. Deviant Behav.: Interdiscip. J. 19: 227-255.

Davis, S. F., Grover, C. A., Becker, A. H., and McGregor, L. N. (1992). Academic dishonesty: Prevalence, determinants, techniques, and punishments. Teach. Psychol. 19: 16-20.

DePaulo, B. M., Kashy, D. A., Kirkendol, S. E., Wyer, M. M., and Epstein, J. A. (1996). Lying in everyday life. J. Pers. Soc. Psychol. 70: 979-995.

Dornbusch, S. M., Carlsmith, J. M., Bushwall, P. L., Ritter, P. L., Leiderman, P. H., Hastorf, A. H., and Gross, R. T. (1985). Single parents, extended households, and the control of adolescents. Child Dev. 56: 326-341.

Dornbusch, S. M., Ritter, P. L., Mont-Reynaud, R., and Chen, Z. (1990). Family decision-making and academic perfromance in diverse high school populations. J. Adolesc. Res. 5: 143-160.

Dryfoos, J. (1990). Adolescents at Risk. Oxford University Press, New York.

Feldman, S. S., Cauffman, E., Jensen, L. A., and Arnett, J. J. (2000). The (un)acceptability of betrayal: A study of late adolescents' evaluations of sexual betrayal by a romantic partner and betrayal of friend's confidence. J. Youth Adolesc. 29: 499-523.

Feldman, S. S., and Weinberger, D. A. (1994). Self-restraint as a mediator of family influences on boys' delinquent behavior: A longitudinal study. Child Dev. 65: 195-211.

Grotevant, H. D., and Cooper, C. R. (1988). The role of family experience in career exploration: A lifespan perspective. In Baltes, P. B., Featherman, D. L., and Lerner, R. M. (eds.), Life Span Development and Behavior. Erlbaum, Hillsdale, NJ, pp. 331-358.

Grusec, J., and Goodnow, J. (1994). Impact of parental discipline methods on the child's internalization of values: A reconceptualization of current points of view. Dev. Psychol. 30: 4-19.

Jensen, L. A. (1996). Coding manual: Ethics of autonomy, community, and divinity. In Different Habits, Different Hearts: Orthodoxy and Progressivism in the United States and India. Unpublished Doctoral Dissertation, University of Chicago.

Jensen, L. A., Arnett, J. J., Feldman, S. S., and Cauffman, E. (2002). It's wrong, but everybody does it: Academic dishonesty among high school and college students. Contemp. Educ. Psychol. 27: 209-228.

Jessor, R., and Jessor, S. L. (1977). Problem Behavior and Psychosocial Development. Academic Press, New York.

Kashy, D. A., and DePaulo, B. M. (1996). Who lies? J. Pers. Soc. Psychol. 70: 1037-1051.

Keltikangas-Jarvinen, L., and Lindeman, M. (1997). Evaluations of theft, lying, and fighting in adolescence. J. Youth Adolesc. 26: 467483.

Kohlberg, L. (1981). The Philosophy of Moral Development. Harper \& Row, San Francisco.

Kohlberg, L. (1984). The Psychology of Moral Development. Harper \& Row, San Francisco.

Lee, K., and Ross, H. J. (1997). The concept of lying in adolescents and young adults: Testing Sweetzer's folkloristic model. MerrillPalmer Q. 43: 255-270.

Lindskold, S., and Waters, P. S. (1983). Categories for acceptability of lies. J. Soc. Psychol. 120: 129-136.

McCord, J. (1990). Problem behaviors. In Feldman, S. S., and Elliott, G. (eds.), At the Threshold: The Developing Adolescent. Harvard University Press, Cambridge, MA, pp. 414-430.

Millar, K. U., and Tesser, A. (1987). Deceptive behavior in social relationships: A consequence of violated expectations. J. Psychol. 122: 263-273.

Moos, R., and Moos, B. (1974). Family Environment Scale (FES). Consulting Psychologists Press, Palo Alto, CA. 
O’Connor, T. G., Allen, J. P., Bell, K. L., and Hauser, S. T. (1996). Adolescent-parent relationships and leaving home in young adulthood. New Dir. Child Dev. 71: 39-52.

Offer, D. (1969). The Psychological World of the Teenager. Basic Books, New York.

Peterson, C. C. (1995). The role of perceived intention to deceive in children's and adult's concepts of lying. Br. J. Dev. Psychol. 13: 237-260.

Peterson, C. C., Peterson, J. L., and Seeto, D. (1983). Developmental changes in ideas about lying. Child Dev. 54: 1529-1535.

Piaget, J. (1932/1965). The Moral Judgment of the Child. The Free Press, New York.

Roth, N. L., and McCabe, D. L. (1995). Communication strategies for addressing academic dishonesty. J. Coll. Stud. Dev. 36: 531541.

Smetana, J. G. (1988). Conceptions of self and social conventions: Adolescents' and parents' reasoning about hypothetical and actual family conflicts. In Gunner, M. R., and Collins, W. A. (eds.),
Minnesota Symposium on Developmental Psychology (Vol. 21). Erlbaum, Mahwah, NJ, pp. 79-122.

Smetana, J. G. (1989). Adolescents' and parents' reasoning about actual family conflict. Child Dev. 60: 1052-1067.

Smetana, J. G., and Asquith, P. (1994). Adolescents' and parents' conceptions of parental authority and adolescent autonomy. Child Dev. 65: 1147-1162.

Stouthamer-Loeber, M. (1986). Lying as a problem behavior in children: A review. Clin. Psychol. Rev. 6: 267-289.

Stouthamer-Loeber, M., and Loeber, R. (1986). Boys who lie. J. Abnorm. Child Psychol. 14: 551-564.

Strickhartz, A. F., and Burton, R. V. (1990). Lies and truth: A study of the development of the concept. Child Dev. 61: 211-220.

Turiel, E. (1983). The Development of Social Knowledge: Morality and Convention. Cambridge University Press, New York.

Weinberger, D. A. (1997). Distress and self-restraint as measures of adjustment across the life span: Confirmatory factor analyses in clinical and nonclinical samples. Psychol. Assess. 9: 132-135. 